\title{
GENERALIZED TRIANGLE INEQUALITY OF THE SECOND TYPE IN QUASI NORMED SPACES
}

\author{
ASIYEH REZAEI AND FARZAD DADIPOUR
}

Abstract. We investigate a generalized triangle inequality of the second type in the framework of quasi normed spaces. More precisely, by using the well-known Aoki-Rolewicz theorem and some quasi normed inequalities, we obtain some regions of $\mathbb{R}^{n}$ which contain the set of all $n$ tuples satisfying the mentioned inequality. Moreover, some reverse inclusions are also discussed. As applications, we deduce some new results associated with generalizations of the triangle inequality in $p$-normed spaces and we get some already known results in a new approach. Mathematics subject classification (2010): 46A16, 47A30, 46B20.

Keywords and phrases: Triangle inequality of the second type, generalized triangle inequality, AokiRolewicz theorem, quasi normed space.

\section{REFERENCES}

[1] T. Aoki, Locally bounded topological spaces, Proc. Imp. Acad. Tokyo, 18, (1942), 588-594.

[2] H. Belbachir, M. Mirzavaziri AND M. S. Moslehian, q-norms are really norms, Aust. J. Math. Anal. Appl., 3, (2006), 1-3.

[3] F. Dadipour, M. S. Moslehian, J. M. Rassias and S. E. Takahasi, Characterization of a generalized triangle inequality in normed spaces, Nonlinear Anal., 75, (2012), 735-741.

[4] S. S. DRAGomiR, Y. J. ChO AND S. S. Kim, Some inequalities in inner product spaces related to the generalized triangle inequality, Appl. Math. Comput., 217, (2011), 5.

[5] H. HudziK and T. R. Landes, Characteristic of convexity of Köthe function spaces, Math. Ann., 294, (1992), 117-124.

[6] R. MALČESKI, Sharp triangle inequalities in quasi-normed spaces, British J. Math. Comput. Sci., 5, (2015), 258-265.

[7] LJ. ARAMBAŠIĆ AND R. RAJIć, On the $C^{*}$-valued triangle equality and inequality in Hilbert $C^{*}$ modules, Acta Math. Hungar., 119, (2008), 373-380.

[8] N. Minculete AND R. PĂLTĂNEA, Improved estimates for the triangle inequality, J. Inequal. Appl., 17, (2017), 1-12.

[9] T. IZUMIDA, K. I. MitANI AND K. S. SAITO, Another approach to characterizations of generalized triangle inequalities in normed spaces, Cent. Eur. J. Math., 12, (2014), 1615-1623.

[10] N. J. Kalton, N. T. Peck and J. W. Roberts, An F-space sampler, London Math. Soc. 89, Cambridge University Press, 1984.

[11] A. E. LiTVAK, The extension of the finite-dimensional version of Krivine's theorem to quasi-normed spaces, Convex Geometric Analysis, Math. Sci. Res. Inst. Publ., 34, (1998), 139-148.

[12] A. PietsCH, History of Banach spaces and linear operators, Springer, Birkhäuser Publisher, 2007.

[13] J. M. RAsSiAs, Solutions of the Ulam stability problem for Euler-Lagrange quadratic mappings, J. Math. Anal. Appl., 220, (1998), 613-639.

[14] S. Saitoh, Generalizations of the triangle inequality, J. Inequal. Pure Appl. Math., 4, (2003), 5.

[15] S. E. Takahasi, J. M. Rassias, S. Saitoh and Y. TaKahashi, Refined generalizations of the triangle inequality on Banach space, Math. Inequal. Appl., 13, (2010), 733-741.

[16] C. Wu AND Y. LI, On the triangle inequality in quasi-Banach spaces, J. Inequal. Pure Appl. Math., 9, (2008). 